\title{
Isonicotinic acid-ligated cobalt (II) phthalocyanine-modified titania as photocatalyst for benzene degradation via fluorescent lamp
}

\author{
Joey Andrew A. Valinton ${ }^{\mathrm{a}, b^{*}}$, Ji Hye Son ${ }^{\mathrm{a}}$, Jeremiah John O. Zafra ${ }^{\mathrm{a}}$, Gil Nonato C. Santos ${ }^{\mathrm{b}, \mathrm{c}}$, \\ Michael Angelo B. Promentilla ${ }^{b, d}$ and Derrick Ethelbhert C. Y $\mathbf{u}^{\mathrm{a}, \mathrm{b}}$
}

${ }^{a}$ Department of Chemistry, College of Science, De La Salle University, 2401 Taft Avenue, Manila, Philippines

${ }^{b}$ Materials Science and Nanotechnology Unit, De La Salle University, 2401 Taft Avenue, Manila, Philippines

'Department of Physics, College of Science, De La Salle University, 2401 Taft Avenue, Manila, Philippines

${ }^{d}$ Department of Chemical Engineering, De La Salle University, 2401 Taft Avenue, Manila, Philippines

\section{H R O N I C L E}

Article history:

Received October 21, 2015

Received in revised form

December 20, 2015

Accepted 7 April 2016

Available online

7 April 2016

Keywords:

Axially-ligated cobalt (II)

phthalocyanine

Photocatalyst

Indoor air pollution

Benzene

Titanium (IV) oxide

Photosensitization

\begin{abstract}
A B S T R A C T
The utilization of bis(isonicotinic acid)phthalocyaninatocobalt (II) [CoPc(isa) $)_{2}$ incorporated on $\mathrm{TiO}_{2}$ has been studied as a photocatalyst to degrade benzene vapor under fluorescent lamp (indoor light) conditions. The photocatalytic activity of $\left[\mathrm{CoPc}(\right.$ isa) 2$]-\mathrm{TiO}_{2}$ compared to $\mathrm{TiO}_{2}$ showed an increase in the extent of degradation. The axial isonicotinic acid ligand attached to $\mathrm{CoPc}$ improved the degradation rate of benzene as compared with unligated $\mathrm{CoPc}-\mathrm{TiO}_{2}$ which may be attributed to the enhancement of electronic structure in the complex due to the additional isonicotinic acid ligand and its possible attachment to the $\mathrm{TiO}_{2}$ surface through the carboxylic acid moiety. Therefore, covalently-linked $\mathrm{CoPc}(\mathrm{isa})_{2}$ to $\mathrm{TiO}_{2}$ can enhance the extent of photodegradation of benzene and other common volatile organic compounds under indoor lighting conditions.
\end{abstract}

\section{Introduction}

Indoor air pollution is an environmental problem that is less addressed, yet very important to be eliminated due to its direct impact on health and the currently increasing indoor human activities attributed to the concern on outdoor air pollution. Photocatalytic oxidation of air pollutants is one of the most efficient ways of eliminating indoor air pollutants wherein photocatalysts are irradiated by incident light to produce electron-hole pairs capable of generating a cascade of redox couples to convert air pollutants into inert compounds. The photocatalysts are composed of low-band gap semiconductors which easily facilitate formation of electron-hole pairs needed for the reaction. ${ }^{1}$ Typically, $\mathrm{TiO}_{2}$ has a band structure that can be reactive towards most compounds upon light activation. ${ }^{2}$ Conventionally,

\footnotetext{
* Corresponding author. Telefax: +63-2-536-0230

E-mail address: joey.valinton@dlsu.edu.ph (J. A. A. Valinton)

(C) 2015 Growing Science Ltd. All rights reserved. doi: $10.5267 /$ j.ccl.2016.4.002
} 
$\mathrm{TiO}_{2}$ photocatalysts require high energy UV light incident radiation for it to be activated; hence, a separate UV lamp is usually required for photocatalytic reactors to be installed for indoor air purification. ${ }^{3}$ Thus, the primary goal of this research is to increase the sensitivity of $\mathrm{TiO}_{2}$ towards visible light, which is present in indoor environments through indoor lighting (fluorescent) which only emits visible radiation.

One way of harvesting visible light without compromising the electronic band structure of $\mathrm{TiO}_{2}$ is through sensitization, by incorporating light sensitive molecules which are capable as electron donors to the photocatalyst. ${ }^{4}$ Many different photosensitizers (PS) were used onto $\mathrm{TiO}_{2}$, commonly on dye sensitized solar cell (DSSC) applications. ${ }^{2}$ Applications of photosensitized $\mathrm{TiO}_{2}$ on indoor air pollutant degradation applications are of less interest, yet a number of molecules have been used including fullyconjugated molecules and metal macrocycle complexes to mitigate various kinds of pollutants. ${ }^{5}$ Phthalocyanines (MPc, $\mathrm{M}=$ metal), with their applications as molecular conductors ${ }^{6}$ and catalysts, ${ }^{7}$ are very promising additives to $\mathrm{TiO}_{2}$. It has been reported that $\mathrm{TiO}_{2}$ impregnated with $\mathrm{MPcs}$ can be used as visible light activated photocatalysts for degrading sulfur-containing compounds ${ }^{8}$ and organic pollutants ${ }^{9}$ in wastewater.

Modification of the structure of MPcs can also enhance the electronic properties of the complex, which can also positively affect photosensitization. Aside from the change in the central atom, addition of substituents on the phthalocyanine periphery can be done, which would influence the light absorption capabilities of the complex, thereby further enhancing $\mathrm{TiO}_{2}$ photosensitization. ${ }^{10}$ Moreover, the substituents can be functionalized to serve as bridging ligands to $\mathrm{TiO}_{2}$ producing an efficient electron transfer from the phthalocyanine photosensitizer.

This paper reports on axial ligation as a modification option on enhancing the electronic structure of phthalocyanines as photosensitizer to $\mathrm{TiO}_{2}$. Axial ligands have the capacity to influence the Pc as photosensitizer through the metal-ligand interaction and it has also been used as an option for modification on DSSC applications. ${ }^{11}$ It can also be used as a bridging ligand from the photosensitizer to the $\mathrm{TiO}_{2}$ surface if the chosen ligand is functionalized. The study involves the usage of isonicotinic acid as an axial ligand which will act as an axial ligand to cobalt (II) phthalocyanine (CoPc) and may eventually bridge the photosensitizer onto the $\mathrm{TiO}_{2}$ surface through the carboxylate moiety.

\section{Results and Discussion}

In order to measure the versatility of the photocatalysts against realistic indoor air pollution conditions, the chamber is designed to depict a static air environment in which the air is poorly circulating and the diffusion of the VOC vapor is limited to the convection and weak air currents. In order to ensure reliability of measuring such conditions, measurements were made onto the chamber with an empty catalyst which showed a statistically constant concentration and peak area and was observed to have no significant leakages. This is due to the air possibly circumventing inside the chamber brought by the sand bath. The conditions were optimized to meet the consistency in the measurement as the catalyst is placed inside the chamber.

The photocatalytic performance of the axially ligated cobalt (II) phthalocyanine-modified titania $\mathrm{CoPc}(\mathrm{IsA})_{2}-\mathrm{TiO}_{2}$ is compared with the photocatalytic activities of plain $\mathrm{TiO}_{2}$ and cobalt (II) phthallocyanine-modified titania $\left(\mathrm{CoPc}-\mathrm{TiO}_{2}\right)$. Benzene vapor was used in the test because it is considered as one of the most common and toxic volatile organic compounds (VOC) indoor air

pollutants. The progress of benzene degradation versus time via the aforementioned photocatalysts are shown in Fig. 1. 


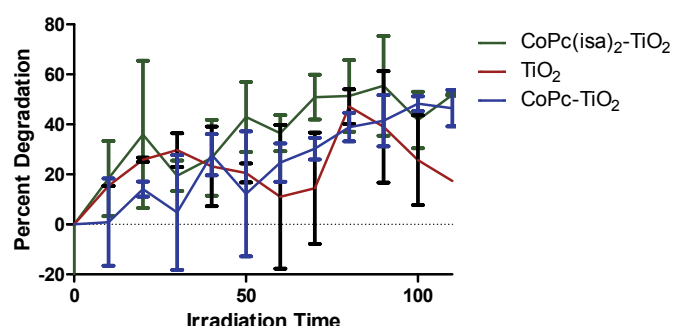

Fig. 1. Photocatalytic degradation of benzene over time

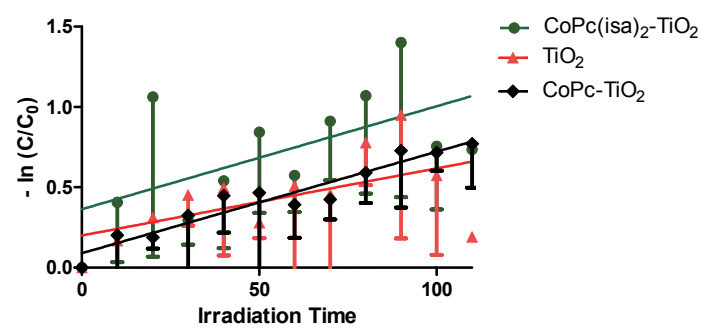

Fig. 2. Pseudo-first order kinetics plot of benzene degradation

It is shown that the instantaneous degradation extent using $\mathrm{CoPc}(\mathrm{isa})_{2}-\mathrm{TiO}_{2}$ is more effective as compared to the other two. When the photocatalytic degradation of benzene was assumed to be a pseudo-first order, it shows that $\mathrm{CoPc}(\mathrm{isa})_{2}-\mathrm{TiO}_{2}$ increased the reaction rate constant due to an increase in the slope of the curve, as shown in Fig. 2.

Upon comparing the statistical correlation of the catalysts with 5\% level of significance, the slopes of $\mathrm{CoPc}$ (isa) $)_{2}-\mathrm{TiO}_{2}$ and $\mathrm{CoPc}-\mathrm{TiO}_{2}$ is significantly nonzero compared to $\mathrm{TiO}_{2}$ which has a slope close to zero. In comparison between $\mathrm{CoPc}$ (isa) $)_{2}-\mathrm{TiO}_{2}$ and $\mathrm{CoPc}-\mathrm{TiO}_{2}$, the rate constant of the former $(k=$ $0.006409)$ slightly greater than that of the latter $(k=0.006320)$ by $1.40 \%$ which shows that the axial ligand functionality does not hinder the photosensitizing capability of $\mathrm{CoPc}$ and it slightly improved the photosensitizer-catalyst interaction.

On a typical photocatalyst like $\mathrm{TiO}_{2}$, photocatalysis can occur by surpassing the band gap by light excitation. This creates an electron in the conduction band and a hole in the valence band, called electron-hole pairs, which facilitates redox processes to adjacent molecules. In indoor environments where ultraviolet radiation is absent, the band structure of $\mathrm{TiO}_{2}$ makes it unable to generate electronhole pairs because the radiant energy provided is not sufficient to overcome the band gap energy for electron excitation. Visible light PS like CoPc are therefore essential for $\mathrm{TiO}_{2}$ to function on indoor environments because they donate electrons directly upon excitation to the conduction band of $\mathrm{TiO}_{2}$, as shown on Fig. 3. The donated electron in the $\mathrm{TiO}_{2}$ conduction band can lead to reduction reactions whereas the ideal PS may regenerate the electron by an oxidation reaction. The $\mathrm{PS}-\mathrm{TiO}_{2}$ composite can then produce an ideal redox couple which can activated by visible light.

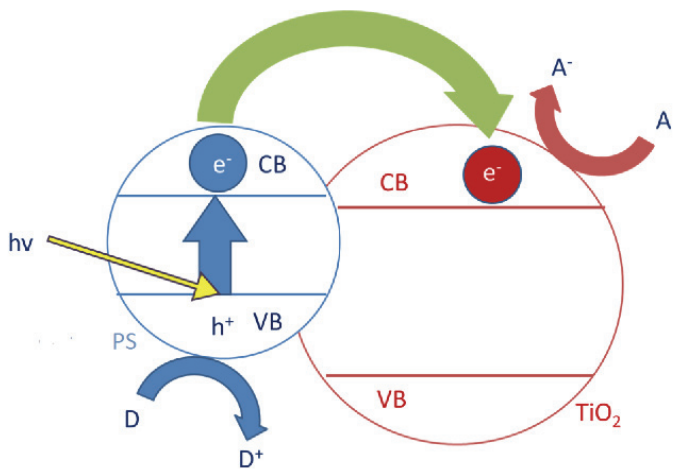

Fig. 3. Mechanism of $\mathrm{TiO}_{2}$ photosensitization

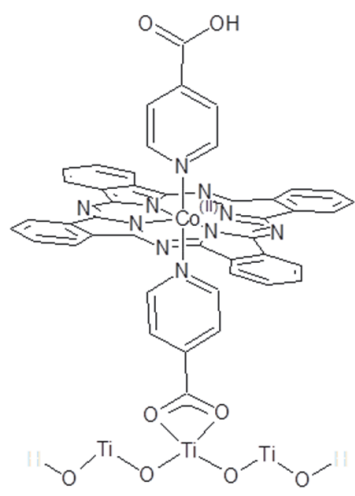

Fig. 4. Structure of $\mathrm{CoPc}(\mathrm{isa})_{2}$ on $\mathrm{TiO}_{2}$ surface

Cobalt (II) phthalocyanine has already been used both as a catalyst ${ }^{12}$ and a visible light photosensitizer for photocatalytic reactions. ${ }^{8}$ Because of this, $\mathrm{CoPc}$ with $\mathrm{TiO}_{2}$ can be versatile in different kinds of lighting conditions. The axial ligation of $\mathrm{CoPc}$ allows enhancement of the electronic capabilities of the complex and functionalize the complex to be used for molecular design. In the study, 
isonicotinic acid was used because of its rigidity due to the pyridine ring and its assembly to $\mathrm{TiO}_{2}$ via its carboxylic acid moiety, a common functionality that provides attachments to metal oxides ${ }^{13}$. The slight improvement in the photocatalytic degradation therefore may be attributed to the isonicotinic acid acting as a bridging ligand to both the cobalt (II) and the titanium in the surface of $\mathrm{TiO}_{2}$, as shown in Fig. 4. This covalent attachment can very essential for an efficient electron transport from photosensitizer to $\mathrm{TiO}_{2}$.

The scheme of photosensitization, therefore, using $\mathrm{CoPc}(\text { isa) })_{2}-\mathrm{TiO}_{2}$ is quite the same with other mechanisms ${ }^{4}$ which involves an electron transfer from the excited complex to the $\mathrm{TiO}_{2}$ conduction band. The $\mathrm{TiO}_{2}$ will be the site for reduction which can react to adjacent oxygen molecules to form reactive oxygen species that degrades pollutants. It has the possibility that $\mathrm{CoPc}$ can also interact with the adjacent gaseous molecules to regenerate the electron loss. In the experiment, however, $\mathrm{Co}^{2+}$ which can be the plausible site for interaction is unavailable due to the coordination of the axial ligands. Despite the limitations of the photosensitizer, $\mathrm{CoPc}(\text { isa) })_{2}$ seemed to perform more efficiently than CoPc. Nevertheless, the efficacy of CoPc with an added axial ligand has not affected the process of photosensitization of $\mathrm{TiO}_{2}$.

\section{Conclusion}

The study has shown that axially ligated-CoPc with $\mathrm{TiO}_{2}\left(\mathrm{CoPc}(\mathrm{isa})_{2}-\mathrm{TiO}_{2}\right)$ photocatalyst has exhibited an increase in the efficiency of the photocatalytic degradation of benzene vapor as compared with its $\mathrm{TiO}_{2}$ and $\mathrm{CoPc}-\mathrm{TiO}_{2}$ counterparts, under ambient indoor lighting (fluorescent lamp).

\section{Acknowledgement}

This project is funded under the Interdisciplinary Research Program of the University Research Coordination Office (URCO) of De La Salle University.

\section{Experimental}

\subsection{In situ synthesis of bis(isonicotinic acid)phthalocyaninatocobalt (II), CoPc(isa) 2}

In a round-bottom flask, $0.25 \mathrm{mg}(0.875 \mathrm{mmol})$ cobalt (II) phthalocyanine ( $\sim 92 \%$ dye content beta form, Tokyo Chemical Industry) was mixed with $0.25 \mathrm{mg}(2.03 \mathrm{mmol})$ isonicotinic acid (ACS grade, Sigma-Aldrich) and was then dissolved in $250 \mathrm{~mL}$ of 1:1 THF:methanol. The mixture was then purged and enveloped with nitrogen and was refluxed at room temperature for 72 hours. The mixture was then filtered and the residue was left at room temperature to dry. The residue appears to be blue-green in color. Yield: $71.42 \%$

ESI-MS (negative mode): $[\mathrm{CoPc}]^{-}=571.0666$ (calculated: $571.49 \mathrm{~m} / \mathrm{z}$ ), $[\mathrm{CoPc}(\mathrm{isa})]^{-}=693.084$ (calculated: $694.61 \mathrm{~m} / \mathrm{z}$ ), [Co(isa) $\left.{ }_{2}\right]_{2}{ }^{-}=606.0350$ (calculated: $610.34 \mathrm{~m} / \mathrm{z}$ )

Differential Thermal Analysis showed endothermic process at $200-275^{\circ} \mathrm{C}$ (isonicotinic acid detachment) and at $500-650^{\circ} \mathrm{C}$ (phthalocyanine decomposition).

\subsection{Photocatalyst Preparation}

In a mortar and pestle, $0.020 \mathrm{~g}$ of $\mathrm{CoPc}$ (isa) $)_{2}$ and $0.5 \mathrm{~g}$ of anatase $\mathrm{TiO}_{2}$ (powder $99.8 \%$, SigmaAldrich) were grinded with drops of Joy Dishwashing Liquid and diluted acetic acid added to the mixture forming a thick paste. The paste was then coated evenly on one side of a $2.5 \mathrm{~cm}$ by $7.5 \mathrm{~cm}$ microscopic glass slide followed by sintering on a hotplate at $200^{\circ} \mathrm{C}$ for 20 minutes. Another photocatalyst was made from $0.5 \mathrm{~g}$ of anatase $\mathrm{TiO}_{2}$ and $0.020 \mathrm{~g}$ of $\mathrm{CoPc}$ using the same procedure. The 
photocatalyst made from only $0.5 \mathrm{~g}$ of $\mathrm{TiO}_{2}$ was made with a sintering temperature of $300^{\circ} \mathrm{C}$ for 20 minutes.

\subsection{Fluorescent (Indoor) Light Photocatalytic Degradation of Benzene Vapor}

The oxidation of benzene vapor was carried out in a fabricated chamber made out of glass with dimensions and details shown in Fig. 4. The chamber was constructed with a removable top to place the glass plates inside with the catalyst facing up. All sides were secured with duct tape to prevent possible vapor leakages. The gastight port is made out of a round PVC fitting with a length of $3 \mathrm{~cm}$ and a diameter of $2.5 \mathrm{~cm}$ and was capped with a rubber septum with the same diameter. The chamber is situated under a sand bath on a hotplate to regulate temperature. The whole setup was placed in a fume cupboard equipped with a $65 \mathrm{~W}$ fluorescent lamp which served as the light source.

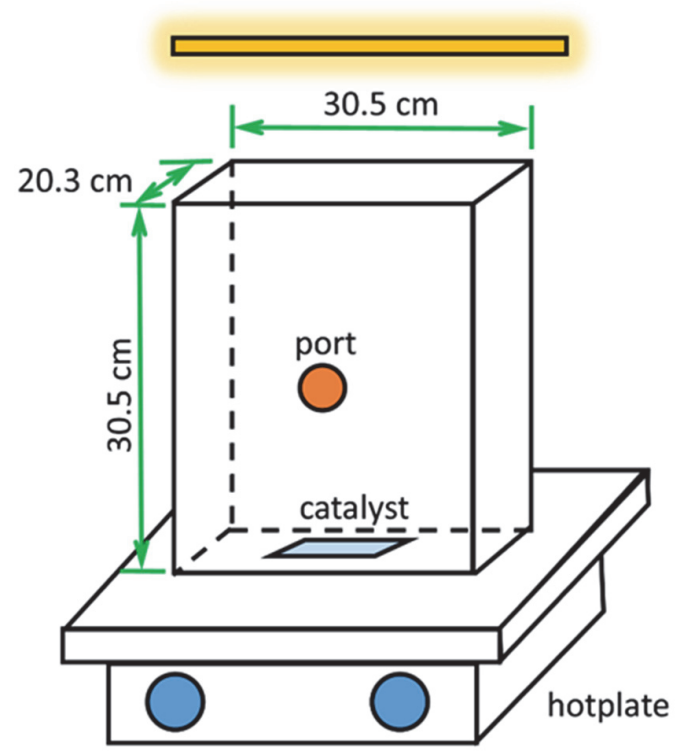

Fig. 5. Schematic of the fluorescent light photocatalytic degradation chamber

The $\mathrm{CoPc}$ (isa) $)_{2}-\mathrm{TiO}_{2}$ photocatalyst was placed inside the chamber which was then securely sealed. With the fluorescent light turned off, $100 \mu \mathrm{L}$ of reagent grade liquid benzene was injected onto the chamber. The chamber was then heated to $80^{\circ} \mathrm{C}$ for ten minutes to evaporate all the benzene before the irradiation starts. 50- $\mu \mathrm{L}$ gas sample increments were collected before irradiation and in 15-minute intervals after irradiation using a gas-tight syringe. The benzene response of the samples was measured using a Perkin Elmer Clarus 500 Gas Chromatograph - Mass Spectrometer with an Elite-5MS capillary column (length $30 \mathrm{~m}$, unternal diameter $0.25 \mathrm{~mm}$, film thickness $0.5 \mu \mathrm{m}$ ). The injection temperature of the chromatograph was set to $250^{\circ} \mathrm{C}$ and the oven temperature is at $60^{\circ} \mathrm{C}$. Each run was set for five minutes and the area of the peak at the 1.8 min retention time was measured.

The extent of benzene degradation was measured assuming that the concentration of the benzene in the gas collected is directly proportional with the peak areas obtained. Due to this assumption, percentage degradation is equivalent to the difference between the peak areas at a certain irradiation period with respect to the unirradiated gas sample, as shown in Eq. (1):

$\%$ degradation $=\frac{A_{0}-A}{A_{0}}$, 
where $A_{0}$ is the peak area obtained before irradiation and $A$ is the peak area obtained on a certain time period. To measure the photocatalytic activity of each, the oxidation of benzene was assumed to be a pseudo-first order reaction. The correlation of the concentrations (based on the peak areas) and the irradiation time was obtained using Eq. (2):

$$
\ln \left(\frac{C}{c_{0}}\right)=\ln \left(\frac{A}{A_{0}}\right)=k t
$$

where $c_{0}$ is the initial concentration in the gas sample and $c$ is the concentration of the gas sample at time $t$. The rate constant of the reaction is represented by $k$ which served as the point of comparison for catalytic efficiency.

\section{References}

1 Linsebigler, A., Lu, G., and Yates, J. (1995) Photocatalysis on $\mathrm{TiO}_{2}$ Surfaces: Principles, Mechanisms, and Selected Results. Chem. Rev., 95 (3) 735-758.

2 Hashimoto, K., Irie, H. and Fujishima, A. (2005) $\mathrm{TiO}_{2}$ Photocatalysis: A Historical Overview and Future Prospects. Jpn. J. Appl. Phys., 44 (12), 8269-8285.

3 Destaillats, H., Sleiman, M., Sullivan, D., Jaquinod, C., Sablayrolles, J. and Molins, L. (2012) Key parameters influencing the performance of photocatalytic oxidation (PCO) air purification under realistic conditions. App. Catalysis B: Environmental, 128, 159-170.

4 Kumar, S. and Devi, L. (2011) Review on Modified $\mathrm{TiO}_{2}$ Photocatalysis under UV/Visible Light: Selected Results on Related Mechanisms on Interfacial Charge Carrier Transfer Dynamics. J. Phys. Chem. A., 115 (46) 13211-13241.

5 Wöhrle, D., Kaneko, M., Nagai, K., Suvorova, O. and Gerdes, R. (2009). Environmental Cleaning by Molecular Photocatalysts, in: Okada, T. and Kaneko, M. (Eds) Molecular Catalysts for Energy Conversion. Springer-Verlag, Heidelberg, 263-297.

6 Inabe, T. and Tajima, H. (2004). Phthalocyanines - Versatile Components of Molecular Conductors. Chem. Rev, 104 (11), 5503-5534.

7 Iliev, V., Alexiev, V., and Bilyarska, L. (1999). Effect of metal phthalocyanine complex aggregation on catalytic and photocatalytic oxidation of sulfur containing compounds. J. Mol. Catalysis A: Chem., 137 (1-3) 15-22.

8 Iliev, V., Tomova, D., Bilyarska, L., Prahov, L. and Petrov. L. (2003). Phthalocyanine modified $\mathrm{TiO}_{2}$ or $\mathrm{WO}_{3}$ - catalysts for photooxidation of sulfide and thiosulfate ions upon irradiation with visible light. J. Photochem. Photobiol. A: Chem., 159 (3) 281-287.

9 Iliev, V. (2002). Phthalocyanine-modified titania - catalyst for photooxidation of phenol by irradiation with visible light. J. Photocchem. Photobiol. A: Chem., 151 (1-3), 195-199.

10 Wang, Z. Mao, W., Chen, H., Zhang, F., Fan, X. and Qian, G. (2006). Copper (II) phthalocyanine tetradulfonate sensitized nanocrystalline titania photocatalyst: Synthesis in situ and photocatalysis under visible light. Catalysis Communications, 7 (8), 518-522.

11 O’Regan, B., Lopez-Duarte, I., Martinez-Diaz, V., Forneli, A., Albero, J., Morandeira, A., Palomares, E., Torres, T. and Durrant, J.R. (2008). Catalysis of Recombination and its Limitation on Open Circuit Voltage for Dye Sensitized Photovoltaic Cells Using Phthalocyanine Dyes. J. Am. Chem. Soc., 130 (10) 2906-2907.

12 Paez-Mozo, E., Gabriunas, N., Maggi, R., Acosta, D., Ruiz, P., \& Delmon, B. (1994). Selective olefin oxidation with cobalt phthalocyanine encapsulated in Y-zeolite. J. Mol. Catalysis, 91 (2) 251-258.

13 Zanotti, G., Angelini, N., Notarantonio, S., Paoletti, A.M., Pennesi, G., Rossi, G., Lembo, A., Colonna, D., Di Carlo, A., Reale A., Brown, T.M., \& Calogero, G. (2010) Bridged phthalocyanine systems for sensitization of nanocrystalline $\mathrm{TiO} 2$ films. Int. J. Photoenergy, Accepted Manuscript (DOI: 10.1155/2010/136807) 